\section{Exam aid?}

\section{Gareth Jones}

Essential Cell Biology. By C. C. Widnell and K. H. Pfenninger. Williams and Wilkins: 1990. Pp. 396. £15.95, \$38.

THE emergence of cell biology as an independent discipline has led to the appearance of two quite outstanding textbooks on the subject that must be familiar to all who have even a passing interest in the subject. Both Molecular Biology of the Cell by Alberts et al. and Molecular Cell Biology by Darnell et al. are large books, each of more than 1,000 pages, reflecting the breadth of the field. As both these textbooks, each now published in a second edition, have been universally highly praised, what need can there be for yet another?

If you read the back cover of Essential Cell Biology, one or two reasons are provided. The publisher suggests that you don't really want to waste time learning all about plants, and that a compact book with the basics clearly identified is all that is required to pass your exam! This book is aimed at preclinical medical students and biology students who wish to learn cell biology only as part of a foundation course. As such it does a good job, the text concentrating on the principles of cell organization, but with substantial coverage of the functions of specialized cells. There is also a well-written section on techniques in cell biology, plus short model answers to study questions set at the end of most chapters.

In any such book, the necessity to compress the available knowledge into the briefest possible space demands a high level of skill from the writer. The authors of this one have relied on the help of specialist contributors in executing this task, with mixed success. The chapter on the nucleus, including cell cycle and cell division, is a model of clarity, as is the substantial section on the organelles associated with secretion, endocytosis and intracellular transport. I wished to read more on collagen assembly, elastin and the functions of proteoglycans in a summary of the components and role of the extracellular matrix, and a contribution on the specialized adhesive junctions of cells was disappointing. The casual reader might understand spot desmosomes to be similar to belt desmosomes and that the intercalated disk of cardiac muscle is composed only of spot desmosomes. Much of this confusion could have been avoided if the author had called a spot desmosome a desmosome and a belt desmosome an adherens junction, these being connection sites for intermediate filaments and actin filaments, respectively.

One innovation to be applauded is a chapter on the morphology of specialized cells, in which readers are presented with electron micrographs of various cell types, together with deductive arguments as to their likely identity. Subsequent chapters deal in a straightforward manner with the nature of cell contractility (but why show a figure of frog skeletal muscle, with triads at the Z-disk, to describe a mammalian system based on a pair of triads per sarcomere?), the cell biology of neurons and hormone actions, including second messengers. There is also a chapter on

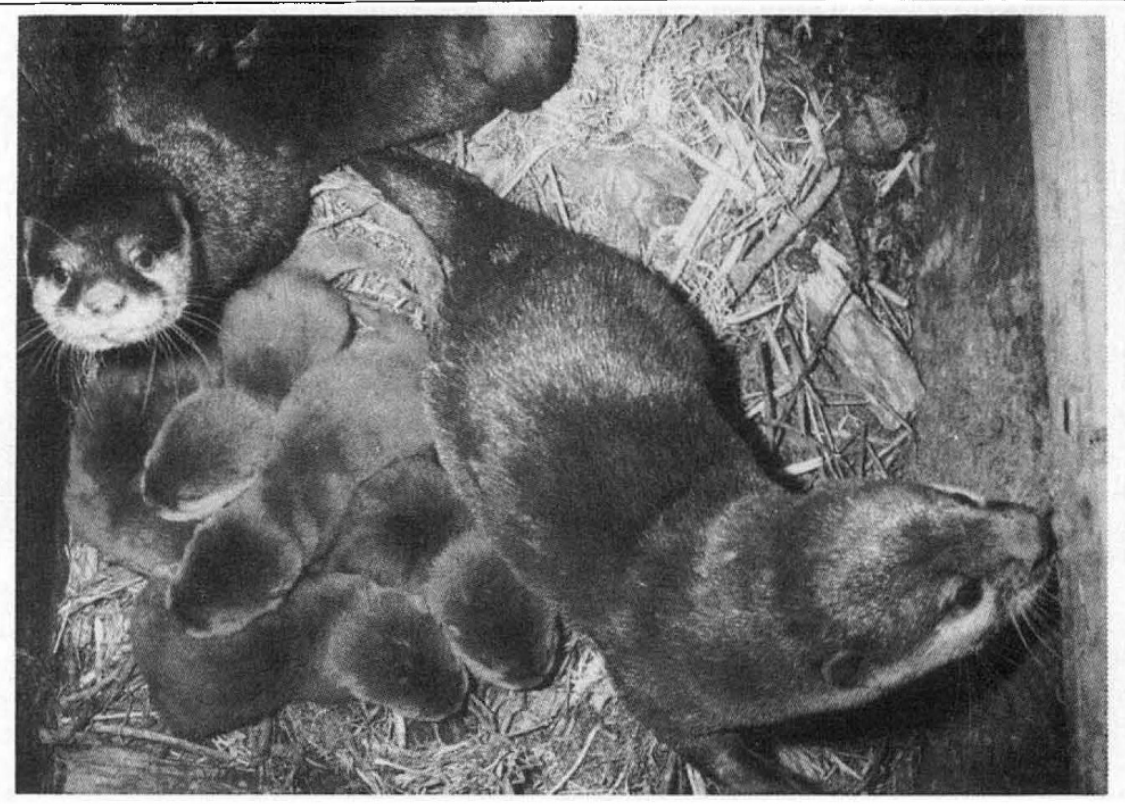

A pair of Asian short-clawed otters with their litter of five cubs. Operation Otter by Philip Wayre is the account of he and his wife's attempt to set up an otter reserve, handrearing cubs in order to return them eventually to the wild, thus helping to preserve this fascinating but endangered animal. Published by Chatto and Windus, price is $\$ 17.95$ (pbk). viral infection which seemed out place; I would have preferred that the space had been used to describe stem cells and the control of cell proliferation. On the whole though, this is a book worth recommending to the target.

Gareth Jones is in the Department of Anatomy and Human Biology, Division of Biomedical Sciences, King's College London, Strand, London WC2R 2LS, UK.

\section{Look, no maths}

\section{I.F. Croall}

Naturally Intelligent Systems. By Maureen Caudill and Charles Butler MIT Press: 1990. Pp. 296. £14.95, \$19.95.

MANY books have appeared over the past couple of years which provide an overview or introduction to the field of neural networks. Here, Caudill and Butler attempt this task with no use of mathematics, aimed at the general reader. Neural networks, or neural computing, is concerned with the use of very much simplified arrays of processing elements based loosely on biological neurons and their interconnection. Applications are predominantly in fields such as pattern recognition, speech, vision and knowledge processing.

The approach the authors adopt is to provide a brief introduction to the differences between neural networks and conventional computers, then to provide a detailed treatment of a range of different network architectures and examples of applications. The avoidance of even the simplest use of mathematical formulae makes some sections rather ponderous, though a reader with no mathematical background might well have had to skip sections had they been more complex. The lack of mathematics also results in the failure of the book to reveal the relationships between the different classes of networks. There is also little attempt to relate networks to the analogous conventional methods, for example the relationship of multilayer perceptrons to other types of function generators or classifiers.

The episodic nature of the chapters makes the book appear like a series of magazine articles. But despite these caveats, the book is well written and produced. It will provide useful access to the ideas of neural computing. A serious omission is any sort of list of references or further reading suggestions. It is also very much an American view of the subject the only Europeans mentioned are Hebb and Kohonen.

I. F. Croall is in the Advanced Computing Department, Hanwell Laboratory, Didcot, Oxfordshire OX11 ORA, UK. 